\title{
Approaches to Inclusion and Social Participation in School for Adolescents with Autism Spectrum Conditions (ASC)-a Systematic Research Review
}

\author{
Johanna Lüddeckens ${ }^{1}$ \\ Received: 11 January 2019 / Accepted: 10 April 2020 / Published online: 4 May 2020 \\ (C) The Author(s) 2020
}

\begin{abstract}
This systematic research review identifies approaches of inclusive education concerning adolescents with autism spectrum (ASC) without intellectual disability (ID). The definitions of inclusion, whose perspectives are taken into account, approaches, and the implications suggested for best practices are reviewed in the articles included in this study. The results show how inclusion is defined as a sense of social acceptance and an approach that physical placement in a regular class can lead to social participation. Taking into account students' perspectives is seen as important. Implications for best practice include information on how to improve school personnel's reflections on their responsibilities and expectations of students with disabilities and points to difficulties for teachers in meeting the diversity of students in the classroom.
\end{abstract}

Keywords Autism spectrum conditions $\cdot$ Inclusive education $\cdot$ Social participation $\cdot$ Perspectives $\cdot$ Approach

\section{Introduction}

The European Agency for Special Needs and Inclusive Education (2018) states that inclusive education and social participation in school are the most important contributing factors for people with disabilities' future social participation in society. Although there are different definitions of the term inclusion in the research, inclusion tends to be identified as students with disabilities being educated in the same environment as their typically developed (TD) peers (Kurth and Mastergeorge 2010; Mesibov and Shea 1996; Norwich 2005; Reed and Osborne 2014). This study focuses on examining the concept of inclusion in school regarding students with autism spectrum conditions (ASC) without intellectual disability (ID) in inclusive school settings; in this article defined as individuals diagnosed with for instance Atypical Autism or Asperger syndrome: individuals with the intelligence quotient $[\mathrm{IQ}]>70$. Unfortunately, this systematic review is unable to cover the vast field of special education;

Johanna Lüddeckens

johanna.luddeckens@mau.se

1 Faculty of Learning and Society, Malmö University, SE-205 06 Malmö, Sweden hence, this search is limited to excluding individuals with ID.

An increasing number of adults with autism became affected by the closure of long-term care hospitals in the UK during the 1970s and 1980s, which, according to Wolf (2004), lead to an increased awareness of the needs of individuals with ASC. This also has led to an increased activity of parent organizations, which developed during the $1960 \mathrm{~s}$ and are now widespread internationally. Not only have such organizations provided information to decision-makers and the public, but they have also established residential and day-care centers for individuals with autism; moreover, they have supported the implementation of evidence-based best practices (Whitaker 2002). According to the American Psychiatric Association (2000), individuals with ASC without ID are characterized as having difficulties with social interactions and as having unusual patterns of interests or behaviors. That is, they can have the same characteristics as those diagnosed with "classic autism." However, individuals with ASC without ID often display cognitive functions within the average to above-average range; sometimes they may demonstrate intellectual functioning at high levels within some areas. Consequently, many students with ASC without ID appear to have the capacity to attend general education classrooms. However, this does not automatically mean that they require only minimal educational 
support in school as a result of demonstrating uneven skills. Due to the severity of their social skills limitations, students with ASC without ID are more likely to be socially isolated by peers (Locke et al. 2010). Moreover, they exhibit mood disorders such as anxiety and depression (Berney 2004). Therefore, students with ASC without ID become stressed and emotionally uncontrollable when faced with change and environmental stressors (Myles 2005 as cited in Sansosti 2012). Previous research also indicates that the adaptive skills for daily living - which require social communication and motor skills, etc. of the students with ASC without ID - are often lower than their intellectual and communicative abilities (Lee and Park 2007; Myles et al. 2007). Hence, this student group often struggles to accomplish a variety of daily tasks (Sansosti et al. 2010). Given these challenges, most of the students with ASC without ID at some point during their schooling will require educational support, despite their higher functioning abilities (Sansosti 2012).

\section{Individuals With ASC Without ID During Adolescence}

As adolescence is a critical period of identity exploration and adjustment, both physically and mentally, this is a period of changing roles within the family and in society (Cronin and Mandich 2015). Adolescence has been described as a time in which family becomes less important, with a greater focus on social contexts outside the family, including peer-relationships, increased independence, and a transition to higher education or employment (Vandell et al. 2005). The transition to adulthood also comes with increased external requirements from school and society, as well as higher expectations of social interaction and social competence. Because adolescents are commonly expected to learn patterns of actions required for participation in society (Farley et al. 2009), this is a particularly challenging period for adolescents with ASC, with the increasing demands of social participation while transitioning to adulthood.

Krieger et al. (2017) used Heart's participation ladder (Hart 1992) in a systematic review of research on supporting and hindering environments for the participation of adolescents with ASC. The Heart ladder describes the participation of children and adolescents in terms of shared decision processes, which, due to their impairments in social interaction and communication, shows that adolescents with ASC might be at risk of being patronized, which can result in reduced shared participation in decision-making (Krieger et al. 2017). Ultimately, this process can result in reduced participation in social and inclusive contexts, both in terms of self-determination and from a social perspective. Krieger et al. (2017) concluded that security and connection are environmental aspects affecting the participation of adolescents with ASC and their desire for positive peer relationship experiences.

\section{Adolescents With ASC Without ID in Social and Inclusive Educational Contexts}

Munkhagen et al. (2017) examined the prevalence of school refusal behavior in 216 students aged 9-16 years (88 with ASD and 138 TD) who were recruited for a cross-sectional study. They found that partial or complete absenteeism assessed at school was present in $42.6 \%$ of students with ASC, compared with $7.1 \%$ of TD students during a 20-day period (Munkhagen et al. 2017). A number of studies have problematized the finding that students with ASC are at greater risk of being bullied than their TD peers (Fernando and Perera 2012; Hwang et al. 2018; Wong 2017; Sreckovic et al. 2014). This phenomenon might also be linked to the difficulties sometimes faced by students with ASC in expressing their emotions regarding situations related to the school setting (Able et al. 2015; Twachtman-Cullen et al. 2006). Hebron and Humphrey (2014) analyzed the risk factors for mental health difficulties affecting individuals with ASC in mainstream secondary schools. A range of factors influence the way students with ASC process, experience, and ultimately make sense of the world around them, and each may contribute to mental health difficulties. Hebron and Humphrey (2014) note that the problems of social and emotional understanding faced by individuals with ASC, including a reduced ability to adopt the perspective of others ("theory of mind" or "metalizing"; BaronCohen 2005), are linked to maladaptive social attribution processes, such as the tendency to infer hostile intention from the behavior of others. This phenomenon has been associated with anxiety and depression (Meyer et al. 2006). The desire for routine, predictability, and "sameness" caused by difficulties understanding the external world can also trigger increased anxiety (Gillott et al. 2001). Some previous studies have indicated that the sense of being different, which is felt particularly strongly by individuals with ASC without ID, might also trigger distress (Bolman 2008; Portway and Johnson 2003; Hebron and Humphrey 2014).

The teacher can play a significant role in the prevention of distress and anxiety among individuals with ASC in an inclusive school setting. Although a previous study by Tennant et al. (2014) reported that teacher support can promote academic competence and prevent problematic behaviors in the classroom, the importance of teacher support for children's social well-being remains unclear (Farmer et al. 2011). However, Chung et al. (2015) state:

It is crucial to address the final limitation, because when teachers' cognitive, emotional and behavioral responses to students with ASD are different from their responses toward typical students, it may lead to not only different 
expectations, but also effect of self-fulfilling prophecies about student performance.

(Chung et al. 2015, p. 3)

Chung et al. (2015) emphasize the importance of teachers' attitudes towards students with ASC when supporting their academic and social success. Falkmer et al. (2012) concluded that teachers' personal interest in teaching students with ASC was correlated with their accuracy in teaching these students, representing important factors to consider when planning for successful placements in mainstream schools. Koegel et al. (2013) note that when teachers (and other school staff) organize school activities in a way that incorporates the preferred interests of adolescents with ASC into the activities organized, students with ASC show an increased level of engagement and an increased rate of initiating social interaction with TD peers.

In this systematic research review, the concept of "approach" refers to the starting point, the viewpoint, or perspective about inclusion and social participation, which can be found in the literature. The previous research introduced in this article highlights the importance of identifying key components of successful inclusion for ASC individuals. However, it is necessary to consider how we define inclusion in research, and its effects. Importantly, the way we in general address inclusive education in society, and how we set the standards for the dominant norms formulates the discourse. According to Foucalt (1972), discourses are "practices that systematically form the objects of which they speak." In this article, this is interpreted as how the approaches of inclusive education are debated in research, how this constitutes social practice, and, ultimately, how it affects the lives of adolescents with ASC.

\section{Aim and Research Questions}

The purpose of the current review is to identify, describe, and analyze different research approaches or angle of incidents, to inclusive education and social participation for adolescents with ASC without intellectual disability (ID, IQ > 70).

The study focused on the following research questions:

A. What research articles about inclusion and social participation for students with ASC without ID fit the inclusion criteria in this study?

B. What are the main definitions of inclusion in the present literature?

C. On whose perspectives are the studies in the current review based (students, teachers, or parents)?

D. What research approaches can be identified in the reviewed studies?

E. What implications for practice, if any, are suggested in the reviewed studies?

\section{Methods}

\section{Study Design}

This study is part of a doctoral project; the systematic data collection and review were conducted under the supervision of two senior researchers. Wiley et al. (2011) divided systematic research reviews into different types. One type is a systematic review that focuses on the examination of complicated or controversial topics, or areas in a field. In this current systematic review, the focus lies within the field of inclusive education for adolescents with intellectual able ASC. Wiley et al. (2011) argued that this type of review plays an important role of identifying, explaining, and providing persuasive perspectives on complicated or controversial issues in the lives of students in need and professionals in education. These reviews are often designed to outline the history of the issue in question, and assess its status by identifying different approaches in research and their implications. Finally, these types of systematic research reviews typically conclude with recommendations for policy and practice (Wiley et al. 2011).

The searches were limited to two known and reliable databases in order to manage a reasonable amount of data, which were selected because of their access to research in the fields of education, psychology, and related disciplines. The aim of this study is to identify the research approaches to inclusive education in the articles reviewed. In addition, to analyze social participation in school for adolescents with ASC without ID. To facilitate the aim, inclusion and exclusion criteria were applied in the search string for various interpretations of the concepts of autism spectrum disorder, social participation, inclusion, and education. Moreover, the string sought to find studies that did not focus on individuals with ID. To find studies that focus on adolescents in secondary school, it also searched for interpretations of secondary schools. The following is the complete search string:

(autism OR asd OR autism spectrum disorder OR asperger's OR asperger's syndrome $O R$ autistic disorder $O R$ aspergers) AND (inclusive education OR participation) AND (social inclusion OR social participation OR social inclusive) NOT (intellectual disability OR mental retardation OR learning disability $O R$ developmental disability OR learning disabilities) AND (high school OR secondary school) NOT (preschool OR kindergarten OR early childhood education)

To limit down the amount of hits in the databases further, due to the later manageability of the data, the results were refined by peer review from the last 5 years (from 2012 to 2017), written in English, age-refined (Database ERIC: Elementary Secondary Education, High schools, High Schools Equivalency Programs, Secondary Education, Postsecondary Education, Junior High Schools; Database PsycINFO: adolescence). The search produced 85 hits (Table 1). Two independent individuals from the Malmö 
Table 1 Databases used for the literature search

\begin{tabular}{lc}
\hline Database & Number of articles \\
\hline ERIC & 1 \\
PsycINFO & 84 \\
Total & 85 \\
\hline
\end{tabular}

University Library staff also verified the search and its results in both databases.

\section{Inclusion and Exclusion Criteria}

Since this study aimed to identify, describe, and analyze different research approaches to inclusive education for adolescents with ASC and without ID, the inclusion criteria (Table 2) restricted the focus to student groups aged 11-21 years old among the 85 articles, and included articles addressing inclusion and social participation in school and society. Systematic research reviews were examined, while medical and/or clinical studies (studies addressing topics such as individuals' communicative or behavioral development) were excluded. The exclusion process is shown in Table 2. Some articles met more than one exclusion criterion (Table 3). After sorting the articles using the inclusion and exclusion criteria, a sample of 15 articles was included in the final review (Table 5).

\section{Inclusion Criteria}

The current study sought to identify research on social participation and/or inclusion in schools and/or society, informing the main inclusion criteria. To further narrow the search, the focus was on adolescents/young adults, which was used as the

Table 2 Inclusion and exclusion criteria

\begin{tabular}{|c|c|c|}
\hline Activity & Inclusion criteria & Exclusion criteria \\
\hline Selection & $\begin{array}{l}\text { 1. Social participation in } \\
\text { school and/or society } \\
\text { 2. Inclusion in school and/or } \\
\text { society } \\
\text { 3. Age group (high school and } \\
\text { secondary school, } \\
\text { adolescents }>11 \text { years old, } \\
\text { young adults }<21 \text { years } \\
\text { old) and student group in } \\
\text { mainstream school, general } \\
\text { education settings, no } \\
\text { specifically defined age } \\
\text { group }\end{array}$ & $\begin{array}{l}\text { 1. Age group (infants, } \\
\text { children in Kindergarten, } \\
\text { primary or elementary } \\
\text { school, preschool, or adults } \\
>20 \text { years old) } \\
\text { 2. Intellectual disabilities } \\
\text { 3. Diagnosis other than ASC } \\
\text { 4. Articles mainly focused on } \\
\text { communicative or } \\
\text { behavioral development } \\
\text { (i.e., medical or clinical } \\
\text { studies) or only in } \\
\text { non-educational contexts } \\
\text { 5. Systematic research } \\
\text { reviews without a specific } \\
\text { focus on inclusion } \\
\text { 6. Book reviews }\end{array}$ \\
\hline
\end{tabular}

third inclusion criterion. This inclusion criteria-type selected studies focused on student groups in mainstream schools, general education settings; no particularly defined age group (i.e., articles in which participants were defined as a more general group of individuals with a certain disability). The study also included articles examining groups of individuals participating in a specific intervention (for instance communicative developmental interventions, or the use of augmentative and alternative communication $[\mathrm{AAC}]$ ). These articles generally included no specific information about participants' age.

\section{Exclusion Criteria}

The current review targeted adolescents, defined as individuals aged 11-21 years. Thus, studies of children between 0 and 10 and adults over 22 years were excluded. Studies focusing on individuals with ASC and intellectual disabilities, or individuals with other disabilities (i.e., attention deficit hyperactivity disorder, or reading and writing impairments), as well as clinical or medical studies mainly focusing on individuals' communicative and/or behavioral development performed in a non-educational context, were also excluded. The results included systematic research reviews, which were generally excluded because of the current study's focus on recent and original research in the area of inclusive education and social participation, unless the main aim was focused on research within the field of the current study. Three systematic research articles were included in the search; two of these studies were excluded because of the first and fourth exclusion criteria. The third systematic research article in the search was included because of its direct link to the purpose and research questions of the current study. One book review was excluded because it was not an original study (exclusion criterion 6).

\section{Selection Process}

The selection process began by reviewing abstracts three times and sorting them according to the inclusion and exclusion criteria described above. The articles that were difficult to define were reviewed by reading the research purpose and discussion sections, and applying the inclusion and exclusion criteria. The articles were then divided into four groups:

I. Articles about individuals with ASC without ID within the specified age range (according to inclusion criterion 3 ).

II. Articles that were mainly medical studies; studies performed in a non-educational context (according to exclusion criterion 4).

III. Articles about individuals with intellectual disability and/or other disabilities other than ASC (according to exclusion criteria 2 and 3 ). 
Table 3 Number of articles excluded by each exclusion criterion

\begin{tabular}{ll}
\hline Exclusion criteria & $\begin{array}{l}\text { Number of articles } \\
\text { excluded }\end{array}$ \\
\hline $\begin{array}{l}\text { 1. Age group (infants, children in kindergarten, primary or elementary school, } \\
\text { preschool, or adults > 20 years old) }\end{array}$ & 27 \\
2. Intellectual disabilities & 10 \\
3. Diagnosis not ASC & 15 \\
4. Articles focused mainly on communicative or behavioral development & 45 \\
(i.e., medical or clinical studies) or only in non-educational contexts & 2 \\
5. Systematic research reviews without a specific focus on inclusion & 1 \\
\hline
\end{tabular}

IV. Systematic research articles, sorted later by research focus, systematic research articles dealing with inclusion in school included (according to exclusion criterion 5).

The remaining articles were examined in full, analyzed, and categorized using a thematic analysis process (Bryman 2015). The differences and similarities were recorded in Excel, providing a visual overview of the content in the articles. The different research areas in each study were noted. After this, the articles were distributed into four groups of research areas/approaches, dealing with topics as social anxiety, best practice for inclusion and participation, the role of the teacher, as well as focusing on individuals with intellectual able ASCs' own perspectives regarding inclusion or participation. These four research approaches are shown in Table 4, and the results of the articles and their individual research approaches are presented in Table 5. A cross analysis was made by the results on research questions $\mathrm{B}, \mathrm{D}$, and $\mathrm{C}$, which are introduced in Table 6, Table 7, and Table 8.

\section{Results}

In this section, the results are discussed - based on and organized by the alphabetical order of the four research questions (A, B, C, and D). Table 5 introduces the data answering the research questions $\mathrm{A}, \mathrm{B}, \mathrm{C}$, and $\mathrm{D}$, as well as a column for a code of reference for each article, later used as references in the cross-analysis tables: Tables 6,7 , and 8 under the rubric
Cross analyze of the results in research questions $B, C$, and $D$. The results answering research question $A$ are presented in Table 5, followed by individual rubrics for research questions $\mathrm{B}$ and $\mathrm{C}$. Research questions D and $\mathrm{E}$ are listed under the same rubrics.

\section{Research Question A: Research Articles About Inclusion and Social Participation for Students}

In Table 5, the research articles that fit the inclusion criteria in this study are introduced.

\section{Research Question B: the Definitions of Inclusion in the Articles}

The results from research question $\mathrm{B}$ can be seen in Table 5 . Nine of the articles found (Baines 2012; Chung et al. 2012; Gotham et al. 2014; Goldingay et al. 2013; Myers et al. 2015; Falkmer et al. 2015; Chen et al. 2016; Rosso 2016; Lounds Taylor et al. 2018) defined inclusion as "being socially accepted in the context and socially participating in the group and in the school" (perspective A). The remaining six articles (Foster and Pearson 2012; Cameron and Cook 2013; Humphrey and Symes 2014; Watkins et al. 2015; Lamb et al. 2016; Taheri et al. 2017) defined inclusion as "being physically placed in mainstream classes, leading to social participation" (perspective B).

Lamb et al. (2016) defined inclusion in reference to different experiences addressed within the social model of disability

Table 4 Research approaches

\begin{tabular}{ll}
\hline Research approach & Number of articles \\
\hline $\begin{array}{l}\text { 1. Social/academic inclusion and participation-level of anxiety } \\
\text { 2. Methods and/or development of best practice for inclusion and social a } \\
\text { nd academic participation for individuals with ASC in school and society }\end{array}$ & 3 \\
$\begin{array}{l}\text { 3. Teachers' perspectives, approaches, and training } \\
\begin{array}{l}\text { 4. Perspectives of individuals with ASC regarding their social and academic } \\
\text { participation in school and society }\end{array}\end{array}$ & 2 \\
\begin{tabular}{l} 
Total \\
\hline
\end{tabular} & 4 \\
\hline
\end{tabular}


Table 5 Articles found, definitions of inclusion, perspectives, research approaches in the articles and article reference code

\begin{tabular}{|c|c|c|c|c|}
\hline RQ A: article & $\begin{array}{l}\text { RQ B: definitions of inclusion } \\
\text { in school and society }\end{array}$ & RQ C: perspective & $\begin{array}{l}\text { RQ D: research } \\
\text { approach }\end{array}$ & $\begin{array}{l}\text { Reference } \\
\text { code }\end{array}$ \\
\hline $\begin{array}{l}\text { Gotham et al. (2014). "Rumination and perceived } \\
\text { impairment associated with depressive symptoms } \\
\text { in a verbal adolescent-adult ASD sample" }\end{array}$ & $\begin{array}{l}\text { Socially accepted in the context and } \\
\text { socially participating in the group } \\
\text { and in the school (A) }\end{array}$ & Students' & 1 & A1 \\
\hline $\begin{array}{l}\text { Chen et al. (2016). "The experience of social par- } \\
\text { ticipation in everyday contexts among individuals } \\
\text { with autism spectrum disorders: An experience } \\
\text { sampling study" }\end{array}$ & $\begin{array}{l}\text { Physical placement in mainstream } \\
\text { classes, leading to social } \\
\text { participation (B) }\end{array}$ & Students' & 1 & $\mathrm{~A} 2$ \\
\hline $\begin{array}{l}\text { Lounds Taylor et al. (2018). "Social participation } \\
\text { and its relation to internalizing symptoms among } \\
\text { youth with autism spectrum disorder as they } \\
\text { transition from high school" }\end{array}$ & $\begin{array}{l}\text { Socially accepted in the context and } \\
\text { socially participating in the group } \\
\text { and in the school (A) }\end{array}$ & Students' (parents') & 1 & A3 \\
\hline $\begin{array}{l}\text { Chung et al. (2012). "Social interactions of students } \\
\text { with disabilities who use augmentative and alter- } \\
\text { native communication in inclusive classrooms" }\end{array}$ & $\begin{array}{l}\text { Socially accepted in the context and } \\
\text { socially participating in the group } \\
\text { and in the school (A) }\end{array}$ & $\begin{array}{l}\text { Students' (through } \\
\text { observations) }\end{array}$ & 2 & A4 \\
\hline $\begin{array}{l}\text { Foster and Pearson (2012). "Is inclusivity an indi- } \\
\text { cator of quality of care for children with autism in } \\
\text { special education?" }\end{array}$ & $\begin{array}{l}\text { Physical placement in mainstream } \\
\text { classes, leading to social } \\
\text { participation (B) }\end{array}$ & Teachers and parents' & 2 & A5 \\
\hline $\begin{array}{l}\text { Watkins et al. (2015). "A review of peer-mediated } \\
\text { social interaction interventions for students with } \\
\text { autism in inclusive settings" }\end{array}$ & $\begin{array}{l}\text { Physical placement in mainstream } \\
\text { classes, leading to social } \\
\text { participation (B) }\end{array}$ & Teachers' and students' & 2 & A6 \\
\hline $\begin{array}{l}\text { Goldingay et al. (2013). "An intervention to im- } \\
\text { prove social participation for adolescents with } \\
\text { autism spectrum disorder: Pilot study" }\end{array}$ & $\begin{array}{l}\text { Socially accepted in the context and } \\
\text { socially participating in the group } \\
\text { and in the school (A) }\end{array}$ & Students' & 2 & A7 \\
\hline $\begin{array}{l}\text { Rosso (2016). "Brief report: Coaching adolescents } \\
\text { with autism spectrum disorder in a school-based } \\
\text { multi-sport program" }\end{array}$ & $\begin{array}{l}\text { Socially accepted in the context and } \\
\text { socially participating in the group } \\
\text { and in the school (A) }\end{array}$ & $\begin{array}{l}\text { University staffs' and } \\
\text { school staffs' }\end{array}$ & 2 & A8 \\
\hline $\begin{array}{l}\text { Taheri et al. (2017). "Exploring factors that impact } \\
\text { activity participation of children and adolescents } \\
\text { with severe developmental disabilities" }\end{array}$ & $\begin{array}{l}\text { Socially accepted in the context and } \\
\text { socially participating in the group } \\
\text { and in the school (A) }\end{array}$ & Parents' & 2 & A9 \\
\hline $\begin{array}{l}\text { Cameron and Cook 2013. "General education } \\
\text { teachers' goals and expectations for their included } \\
\text { students with mild and severe disabilities" }\end{array}$ & $\begin{array}{l}\text { Socially accepted in the context and } \\
\text { socially participating in the group } \\
\text { and in the school (A) }\end{array}$ & Teachers' & 3 & A 10 \\
\hline $\begin{array}{l}\text { Humphrey and Symes (2014). "Inclusive Education } \\
\text { for Pupils with Autistic Spectrum Disorders in } \\
\text { Secondary Mainstream Schools: Teacher } \\
\text { Attitudes, Experience and Knowledge" }\end{array}$ & $\begin{array}{l}\text { Socially accepted in the context and } \\
\text { socially participating in the group } \\
\text { and in the school (A) }\end{array}$ & Teachers' & 3 & A11 \\
\hline $\begin{array}{l}\text { Baines (2012). "Positioning, strategizing, and } \\
\text { charming: How students with autism construct } \\
\text { identities in relation to disability" }\end{array}$ & $\begin{array}{l}\text { Socially accepted in the context and } \\
\text { socially participating in the group } \\
\text { and in the school (A) }\end{array}$ & Students' & 4 & A12 \\
\hline $\begin{array}{l}\text { Myers et al. (2015). "Community and social partic- } \\
\text { ipation among individuals with autism spectrum } \\
\text { disorder" }\end{array}$ & $\begin{array}{l}\text { Socially accepted in the context and } \\
\text { socially participating in the group } \\
\text { and in the school (A) }\end{array}$ & Students' & 4 & A13 \\
\hline $\begin{array}{l}\text { Falkmer et al. (2015). "Can you see it too? Observed } \\
\text { and self-rated participation in mainstream schools } \\
\text { in students with and without autism spectrum } \\
\text { disorder" }\end{array}$ & $\begin{array}{l}\text { Socially accepted in the context and } \\
\text { socially participating in the group } \\
\text { and in the school (A) }\end{array}$ & Students' & 4 & A14 \\
\hline $\begin{array}{l}\text { Lamb et al. (2016). "Capturing the world of physical } \\
\text { education through the eyes of children with au- } \\
\text { tism spectrum disorders" }\end{array}$ & $\begin{array}{l}\text { Physical placement in mainstream } \\
\text { classes, leading to social } \\
\text { participation (B) }\end{array}$ & Students' & 4 & A 15 \\
\hline
\end{tabular}

(Oliver 1990). The model "provides a way of conceptualizing the disadvantage experienced by people with impairments which emphasizes the social, economic and environmental barriers to participation in society" (Burchardt 2004, p. 735). Different versions of this model have highlighted inclusion issues within schools (Fitzgerald 2012), illuminating the need for curriculum reform (Kirk 2005) and measures to ensure inclusive physical education (PE) experiences, rather than expecting disabled pupils to "fit in" (Lamb et al. 2016). Another study emphasized the importance of a whole-school approach to inclusion (Booth and Ainscow 2002). Regarding the inclusion of students with ASC, it has been argued that just 
Table 6 Cross analysis between RQ B (definitions of inclusion) and RQ C (perspectives)

\begin{tabular}{|c|c|c|c|}
\hline $\begin{array}{l}\text { Definition of inclusion } \\
\text { (RQ B) }\end{array}$ & $\begin{array}{l}\text { Total number of } \\
\text { articles }\end{array}$ & $\begin{array}{l}\text { Perspective }(\text { RQ C })=\text { number } \\
\text { of articles }\end{array}$ & References \\
\hline \multirow[t]{3}{*}{ A } & \multirow[t]{3}{*}{9} & Students' = 7 (3) & $\begin{array}{l}\mathrm{A} 1, \mathrm{~A} 3, \mathrm{~A} 4, \mathrm{~A} 7, \mathrm{~A} 12, \\
\quad \mathrm{~A} 13, \mathrm{~A} 14\end{array}$ \\
\hline & & Parents' = 1 (2) & A3, A9 \\
\hline & & Teachers' = 1 & $\mathrm{~A} 8, \mathrm{~A} 10, \mathrm{~A} 11$ \\
\hline \multirow[t]{3}{*}{ B } & \multirow[t]{3}{*}{4} & Students' $=2(3)$ & A2, A6, A15 \\
\hline & & Parents' $=1$ & A6 \\
\hline & & Teachers' = 1 (2) & A5, A6 \\
\hline
\end{tabular}

a few members of staff cannot achieve positive outcomes. Rather, schools must buy in to inclusion wholesale if the approach is to be successful. Inclusion cannot rely on the interest, commitment, and enthusiasm of one or two individuals. Without a shift in the whole organization's attitude and approach, it will fail children with autism and Asperger's syndrome, Barnard et al. (2000) states. By this, they mean a joint understanding in the organization of what inclusion really is, having mutual goals such as common values and that all students getting access to the education and to the social life in school, in this case students with ASC. Humphrey and Symes (2014) argue, in accord with previous studies (Eldara et al. 2010; Huang and Wheeler 2007), that whole-school inclusion requires all staff to have a clear and shared understanding of the aims and expectations of inclusion within their school, and these must be supported by senior management (Horrocks et al. 2008).

Overall, the concept of inclusion in the reviewed articles tended to highlight physical placement in mainstream class leading to social participation, as well as being socially accepted in the context and socially participating in the group and in the school. A key component of successful inclusion and social participation for students with SEN/disabilities suggests the need for a united whole-school approach towards inclusion.

\section{Research Question C: Perspectives}

The results from research question $\mathrm{C}$ can be seen in Table 5; however, studies taking the first research approach: Social/ academic inclusion and participation-level of anxiety, tended to consider students' perspectives (Gotham et al. 2014; Chen et al. 2016; Lounds Taylor et al. 2018). One of the studies also considered parents' perspectives (Lounds Taylor et al. 2018). Studies taking the second research approach: Methods and/or development of best practice for inclusion and social and academic participation for individuals with ASC in school, tended to focus on the perspectives of the school staff or parents (Foster and Pearson 2012; Watkins et al. 2015; Goldingay et al. 2013; Rosso 2016; Taheri et al. 2017). One of these studies also considered students' perspectives (Watkins et al. 2015), while one focused on the student perspective through observations (Chung et al. 2012). Studies taking the third research approach: Teachers' perspectives, approaches and training, considered the perspectives of the teachers (Cameron and Cook 2013; Humphrey and Symes 2014). The studies taking the fourth research approach: Perspectives of individuals with ASC regarding their social and academic participation in school and society, considered students' perspectives (Baines 2012; Myers et al. 2015; Falkmer et al. 2015; Lamb et al. 2016). Overall, the fifteen articles found focus on three perspectives: the students', the teachers', and the parents' perspectives.

\section{Research Questions D and E: Research Approaches and Their Implications for Practice}

The approaches found in this review are categorized into themes, with each theme (approach) sharing the same content focus.

\section{First Research Approach: Social/Academic Inclusion and Participation-Level of Anxiety}

Gotham et al. (2014) examined the relationships between depressive symptoms and several psychosocial constructs
Table 7 Cross analysis between RQ B (definitions of inclusion) and RQ D (research approach)

\begin{tabular}{llll}
\hline $\begin{array}{l}\text { Research approach } \\
\text { (RQ D) }\end{array}$ & $\begin{array}{l}\text { Dominating definition of } \\
\text { inclusion (RQ B) }\end{array}$ & Number of articles & References \\
\hline 1 & A & 2 of 3 & A1, A3 \\
2 & A & 4 of 6 & A4, A7, A8, A9 \\
3 & B & 2 of 2 & A10, A11 \\
4 & A & 3 of 4 & A12, A13, A14 \\
\hline
\end{tabular}


Table 8 Cross analysis between RQ C (perspectives) and RQ D (research approach)

\begin{tabular}{|c|c|c|c|}
\hline $\begin{array}{l}\text { Research approach } \\
\text { (RQ D) }\end{array}$ & Total number of articles & $\begin{array}{l}\text { Perspective }(\mathrm{RQ} C)= \\
\text { number of articles }\end{array}$ & References \\
\hline 1 & 3 & $\begin{array}{l}\text { Students' = } 3 \\
\text { Parents' = } 0(1) \\
\text { Teachers' }=0\end{array}$ & $\begin{array}{l}\mathrm{A} 1, \mathrm{~A} 2, \mathrm{~A} 3 \\
\mathrm{~A} 3\end{array}$ \\
\hline 2 & 6 & $\begin{array}{l}\text { Students = } 2(3) \\
\text { Parents' = } 1(2) \\
\text { Teachers' = } 1 \text { (3) }\end{array}$ & $\begin{array}{l}\text { A4, A6, A7 } \\
\text { A5, A9 } \\
\text { A5, A6, A8 }\end{array}$ \\
\hline 3 & 2 & $\begin{array}{l}\text { Student' s }=0 \\
\text { Parents' }=0 \\
\text { Teachers' }=2\end{array}$ & A10. A11 \\
\hline 4 & 4 & $\begin{array}{l}\text { Students' }=4 \\
\text { Parents' }=0 \\
\text { Teachers' }=0\end{array}$ & $\mathrm{~A} 12, \mathrm{~A} 13, \mathrm{~A} 14 . \mathrm{A} 15$ \\
\hline
\end{tabular}

(insight into one's own autism symptoms, rumination, desire for social interaction, and satisfaction with social support) that potentially play a role in the development or preservation of depression among adolescents with ASC. The findings suggested that to ruminate upon one's own autism-related impairment might be related to depressive symptoms in adolescents with ASC, regardless of their "true" degree of impairment (i.e., examiners' perceptions of their autism-related symptoms on the same scale). In addition to the association between rumination and preservation, it has been suggested that low self-esteem can function as an important proponent of depressive symptoms. Thus, there is the indication that individuals with ASC are more likely to perpetuate routines, rituals, and circumscribed interests (Gotham et al. 2014).

In accord with the study described above, Chen et al. (2016) examined the experience of anxiety in social situations among individuals with ASC. The authors reported a correlation between individuals with less severe autism and high social anxiety with less social engagement. However, the results indicated that severe social anxiety was only weakly correlated with "feeling lonely," suggesting that individuals with less severe ASC symptoms did not seek fewer social interactions. Rather, these individuals were less likely to experience high levels of interest and enjoyment in solitary or parallel leisure activities compared with people with more severe ASC, despite social challenges (Carrington et al. 2003; Howard et al. 2006; Müller et al. 2008; Chen et al. 2016)

Lounds Taylor et al. (2018) analyzed how unstructured (e.g., spending time with friends or co-workers) and structured (e.g., attending social events at a place of work, socializing with sports teams) social participation changed from before to after high school for young people with ASC. They also examined the longitudinal and concurrent relationships between social participation and internalizing symptoms. The results indicated no average change in participation after leaving high school, although some individual variability was observed. Participation in structured social activities within this group of individuals was significantly reduced after leaving high school. Young people with more structured social participation in high school were substantially more likely to experience increases in unstructured social participation after leaving high school. In terms of the relationships between internalizing and social activities, a high level of internalizing symptoms while young people with ASC were in high school significantly predicted increasing social isolation after leaving high school, for both structured and unstructured activities.

Overall, the reviewed articles suggested that anxiety and anxiety-loaded activities prevent respondents from being able to participate to the extent they desire.

Implications for Practice in the First Research Approach The articles reviewed in relation to the first research approach focused on social inclusion and exclusion, as well as social and academic participation in relation to individuals' levels of anxiety. Gotham et al. (2014), as well as Lounds Taylor et al. (2018), suggested that adolescents with high levels of rumination about one's own autism-related impairment, as well as those who internalized symptoms while at high school, may be at greater risk of depression and declining participation in social activities after leaving high school. An understanding of the ways in which social and other activities might influence the internalization of symptoms in adolescents with ASC is important, as they are amenable to intervention, and could potentially provide an avenue for improving mental health (Lounds Taylor et al. 2018). Chen et al. (2016) proposed that strategies for dealing with anxiety, in addition to research approaches to improving social skills and providing medication for 
mental health conditions, are included among the measures available to young people with less severe ASC symptoms and higher levels of social anxiety.

\section{Second Research Approach: Methods and/or Development of Best Practice for Inclusion and Social and Academic Participation for Individuals with ASC in School and Society}

Chung et al. (2012) evaluated naturally occurring social interactions for students with disabilities (e.g., ASC) who use augmentative and alternative communication (AAC) in general education classrooms. They found that most of the time students almost exclusively interacted with an assigned staff member as their primary support, such as special teachers or paraprofessionals, and they tended to play a somewhat passive role within the interaction. The authors also reported that students with AAC systems infrequently used their devices; instead, they primarily relied on facial expressions, gestures, and vocalizations within the interactions. Goldingay et al. (2013) evaluated and analyzed a model for developing social interaction among adolescents with ASC and suggested that direct interventions, such as interventions in social training and social interaction designed especially for the individual participant, might have a positive effect.

Similar to Chung et al. (2012) and Goldingay et al. (2013), Watkins et al. (2015) evaluated social interaction through reviewing the effectiveness of different interventions based on interactions between students with ASC and their peers. The results implied that using peer-mediated interventions (PMI) when fostering social interactions among students with ASC shows promise. A study by Rossos (2016) indicated that the use of specially designed coaching strategies and programs in sports education was a critical factor when fostering socialization and developing social skills among students with ASC.

Foster and Pearson (2012) analyzed whether the proportion of time spent in an inclusive educational setting functioned as a process indicator of the quality of schooling for children with autism, thus improving key outcomes. The researchers found no systematic indication that the level of inclusivity improved key future outcomes. However, as introduced in the introduction of this article, The European Agency for Special Needs and Inclusive Education (EA; 2017) studied this issue in further detail, examining a large-scale sample. In line with Foster and Pearson (2012), it showed that inclusive education for students with SEN/disabilities in mainstream schools improved the level of inclusion later in adulthood. Taheri et al. (2017) reported that higher levels of adaptive behavior, greater parental socialization, and placement in integrated school programs were significant predictors of greater participation in activities.
Implications for Practice in the Second Research Approach Research approach 2 deals with methods and/or development, including best practice for inclusion and social and academic participation for individuals with ASC in school and society. For example, Chung et al. (2012) emphasized the importance of interaction opportunities being carefully planned rather than haphazardly hoped for, when dealing with students using ACC. In addition, the authors argued that students must have ongoing access to functional and appropriate AAC systems, be equipped to be active communicators, and be supported by staff with high expectations and a desire for meaningful interactions among the students with whom they work (Chung et al. 2012). In accord with this research approach, Watkins et al. (2015) systematically examined research on PMI in their article, suggesting that it provides a promising approach for promoting social interaction between students with ASC and their peers in inclusive settings.

Foster and Pearson (2012), meaning inclusion as physical placement in mainstream classes, leading to social participation (B), reported that inclusivity did not improve educational or functional outcomes for students with ASC, concluding that, in essence, schools have failed to meet their obligations to these young people. The authors emphasized the need for better instruments to evaluate education outcomes among this student group, calling for a more comprehensive understanding of inclusivity and other potential measures of educational quality, while noting that this may have to wait for both better data and methods. Rosso (2016) also called for future developments of better coaching strategies for students with ASC, using the case of PE. In addition, Rosso (2016) advocates for measurements of this type of education, as well as the investigation of motivational strategies for adolescents with ASC. Like Foster and Pearson (2012), Taheri et al. (2017) examined parents' perspectives, suggesting the importance of efforts to develop the social skill level of both parents and children, in accord with the finding that parental social skill level has an indirect effect on children.

\section{Third Research Approach: Teachers' Perspectives, Approaches, and Training}

Studies utilizing the third research approach focused on the role of the teacher, including teachers' approaches with and expectations of students with ASC, which was the reported purpose of both of the reviewed articles using this research approach. In one study, Cameron and Cook (2013) reported that teachers typically aimed for students with ASC to develop socially, make friends and interact with their peers, and tended to emphasize the beneficial effects of inclusive education for all students. Teachers were also adamant about the goal of supporting TD students to behave in a more accepting way towards students with disabilities. To support all students to improve their 
behavioral skills was emphasized by teachers as one of the most important goals. However, teachers felt that they had lower expectations regarding their own ability to engender positive outcomes for included students with severe disabilities. Teachers reported that the attention to the academic instruction of students with disabilities distracted from the teaching of "core" students. Generally, teachers in the study assumed that students with disabilities were not the responsibility of the general education system, which, according to the researchers, unsurprisingly showed that teachers generally professed a lack of knowledge about educating students with severe disabilities (Cameron and Cook 2013).

Overall, previous studies have reported that teachers tend to indicate positive attitudes towards inclusion and that teachers with more moderate views on integration were more likely to feel that there were high levels of inclusion within their school (Humphrey and Symes 2014). In line with Cameron and Cook's (2013) findings, respondents in a study by Humphrey and Symes (2014) revealed that the potential key benefits for mainstream pupils without ASC that could be gained from interacting with a child with ASC integrated into mainstream classes included increased understanding and tolerance of people different to themselves. However, regardless of these positive attitudes towards including students with ASC into mainstream classes, teachers expressed concern about potential problems associated with integrating this student group (Humphrey and Symes 2014).

\section{Implications for Practice in the Third Research Approach One} of the two articles focused on the third research approach (dealing with the teachers' perspectives, approaches, and training) suggested that generic training for all school staff about students with ASC might not be appropriate. Rather, teachers reported a preference for informed, targeted training for all groups working directly with students with ASC (Humphrey and Symes 2014).

Cameron and Cook (2013) reported that teachers' goals and expectations for students with disabilities in their class conformed to their perceptions of how apparent the child's disability was. This led teachers to conclude that they might have little to offer to this group of students, beyond an opportunity to socialize with other children, resulting in a reduction of learning opportunities for students with disabilities. The authors therefore recommended that school staff take time to reflect on the different goals and expectations they hold in relation to this student group, and to consider how these beliefs may affect student achievement and development. In addition, for teachers to set realistic, challenging, and appropriate goals for the students with disabilities in their classes, it may be necessary to address the finding that general education teachers do not consider themselves primarily responsible for educating students with severe disabilities (Cameron and Cook 2013).
Fourth Research Approach: Individuals with ASCs' Own Perspective/View on Their Social and Academic Participation in School and Society

This research approach deals with identity formation, social stigma, social acceptance and self-acceptance, anxiety, and the positive and negative feelings of being or not being part of a social context. Adolescence is a time of a transition from childhood to adulthood, where social interaction clearly shapes personality. Baines (2012) characterizes adolescence as follows:

For young people, words and actions serve as a measure of where they stand in the social hierarchy of ability, potential, and acceptance. Everything they say and do forms patterns of behavior used to judge what they are capable of, how they measure up to peers, and whether their participation is valued. Students with the label of autism are often studied in terms of what makes them 'different' from others. Instead, Bagatell (2004) suggests the identities of people with autism are not an underlying substance to be discovered, but constructed in social worlds through engagement. Instead of focusing on the individual student, this approach attempts to understand the personal, institutional, and sociocultural storylines that make up their lives.

(Baines 2012, pp. 547-548)

Baines (2012) examined the worldviews of adolescents with ASC over a relatively long period, suggesting that disability labels influenced these students across different contexts in ways that shaped their future life trajectories. Baines (2012) notes that perceptions of ability and disability continuously emerged through social interactions, playing a central role in shaping how a person identifies themselves as learners. The ongoing interplay of relating to the surrounding society's labeling and demands about following certain norms can be distressing. Chen et al. (2016) examined the anxiety induced by the pressure of having to take part in social activities, from the perspectives of individuals with ASC. The findings suggested that people with more severe ASC symptoms were more likely to experience greater "interest" and "enjoyment" in "solitary/parallel leisure" than those with less severe ASC. Participants with high social anxiety were more likely to experience high levels of "in-the-moment anxiety" while engaging in "productive" or "social" activities than those with lower levels of social anxiety. In addition, social anxiety was also found to moderate experiences (Chen et al. 2016).

Some situations and environments in the school feel safer than others do. Lamb et al. (2016) examined the experiences of adolescents with ASC during PE in school. Respondents reported that situations involving the teacher's presence or being in the teacher's office felt safe. These situations and 
places with contiguous spaces provided a micro-space for these students, and were regarded positively, as were activities that provided opportunities for engagement with peers. Opportunities to be celebrated by peers, such as scoring a goal for their team or being given an official role, were found to be important factors, as was the opportunity to engage in team sports. However, students' interactions with changing rooms and corridors were associated with trepidation, worry, and fear (Lamb et al. 2016).

Researchers have attempted to explore the perspectives of adolescents with ASC regarding their social participation in a mainstream inclusive school (Falkmer et al. 2015; Lamb et al. 2016). Falkmer et al. (2015) revealed that though students with ASC participated less frequently in activities in school, they were not less involved when they participated in comparison to their classmates. When comparing perceived participation in school activities and social interaction between students with and without ASC, the results revealed a discrepancy between students' self-rated/perceived participation and their observed participation in interactions. This pattern was not restricted to students with ASC but was found for all students. The results also disclosed higher levels of involvement in parallel activities among students with ASC compared with their classmates. In particular, this was in reference to situations where a student was observed in proximity to classmates, was participating in an activity in which the student was using the same materials as the classmates, and with no observable ongoing social interaction (Falkmer et al. 2015).

Implications for Practice in the Fourth Research Approach In one study using this research approach, Baines (2012) examined the perspectives of individuals with ASC regarding their social and academic participation in school and society. Based on the results, Baines (2012) argues that practitioners should not assume that young people with the label of autism are isolated from the sociocultural process of identity development. Rather, the author emphasizes that these students make a deliberate effort to promote a positive perception of themselves in the eyes of others. Further, Baines (2012) suggests that, as researchers and practitioners, it is important to recognize these efforts and find ways to disrupt patterns of interaction that position students with disabilities in ways that limit their opportunities to participate in full. Moreover, it is important to improve societal understanding about how to best advocate for adolescent individuals with ASC, whether through professional case management services or in the education of families. Myers et al. (2015) argue that schools, caregivers, families, professionals, and legislators must recognize the impact that diminished participation in society and social contexts has for this vulnerable population.

Falkmer et al. (2015) analyzed the degree to which participation can be measured through observation and self-rated interactions for students with and without ASC, examining involvement in parallel activities, and social interactions in school settings. The results revealed that students with ASC showed higher levels of involvement in parallel activities compared with their classmates. Falkmer et al.'s (2015) findings also raise the question of whether students with ASC have as many opportunities for social interaction as they desire.

In studies of PE, some researchers have suggested that there may be a misconception about the way inclusion is understood by some PE departments that emphasize the modification of planning to accommodate students with SEN or disabilities rather than planning to their individual needs (Fitzgerald 2012; Smith 2004). Rather, Lamb et al. (2016) suggest that the appropriate focus for inclusion must be levels of ability, careful differentiation, variety in teaching styles, and approaches to assessment, while paying careful attention to adapting or modifying facilities, equipment, and activities. Further, Lamb et al. (2016) recognize the contextual reality of the emotive and powerful feelings of adolescents with ASC in their study in relation to PE. Fitzgerald (2012) notes that this finding highlights that each individual with ASC is different, and that manipulating the delivery of activities or the group composition does not equate to inclusive practice. Other researchers argue that it is crucial for teachers to plan for inclusion through informed awareness of the barriers pupils may face, which extend to actual and conceptual fields beyond the formal space of lesson delivery (Lamb et al. 2016).

\section{Cross Analyze of the Results in Research Questions B, C, and D}

The results from research questions $\mathrm{B}, \mathrm{C}$, and D were cross analyzed triangularly, which resulted in three tables (Table 6, Table 7, and Table 8). Some of the articles focused on two perspectives (for example both teachers and students or both teachers and parents), hence some of the values with in parentheses.

\section{Discussion}

\section{Defining Inclusion Through Diverse Perspectives}

Overall, two predominating definitions of inclusion can be seen in these articles: A-inclusion as being socially accepted in the educational context and socially participating in the group and in the school, and B-inclusion as being physically placed in mainstream class, thus leading to social participation. The majority of articles focus on student perspectives, which perhaps not surprisingly define inclusion according to definition $\mathrm{A}$. The definition $\mathrm{B}$, meaning the concept of inclusion as social participation being reached through physical placement in mainstream class, is largely taken by the articles 
focusing on teachers and/or parents. This visualizes in the cross analysis in Table 7, where this definition of inclusion is the focus in the two articles in the third research approach about teachers' perspectives, approaches, and training. However, applying this definition of inclusion, one must take into account the difficulties some individuals with ASC face, such as perceptual sensitivity, which can result in difficulties in sorting impressions such as sound, light, scent, and touch, as well as difficulties in social interaction. The barriers of this must be reduced and a learning environment for diversity preassembled, supporting these individuals. Stakeholders who applies the definition B tend sometimes to reject the thought of students being taken out from the mainstream classroom in order to receive education. Applying the definition A however opens up a somewhat more flexible interpretation of the concept of inclusion. Maybe inclusion instead is better off being translated into a sense of coherence in which the individual describe its situation as "comprehensive," "manageable," and "meaningful" (Antonovsky 1987). Considering the students' perspective therefore gets essential.

The majority of articles reviewed in the current study base on the perspectives of ASC students. These perspectives make an important contribution to knowledge that can inform the development of successful practices for individuals with ASC, both in schools and in later working life and other social settings. This understanding can help create best practices and methods for supporting a higher level of participation for individuals with ASC. Considering the views of teachers and parents also helps to broaden students' individual perspectives. However, these perspectives sometimes diverge, raising questions about whose perspective prevails.

\section{Implications for Practice}

The different research approaches described in the current study involve many points of convergence. Ultimately, these research approaches are united by the concept of inclusion, the prospect of participation in school and society, and the outcomes at both an individual level and a societal level. Some of the articles summarize the concept of inclusion as physical placement or presence, while others include both physical placement and the possibility of developing successful inclusion. Overall, the results of the present review emphasize the importance of a united whole-school attitude towards inclusion. The studies in this article calls for best practices with carefully planned interaction opportunities for students with ASC, rather than haphazardly hoped for (Chung et al. 2012). They also calls for best practices using better instruments for evaluating education outcome for this student group (Foster and Pearson 2012), calling for a more comprehensive understanding of inclusivity and other potential measures of educational quality. In sum, it repeatedly comes down to the concept of inclusion, how this concept is being interpret, understood, implemented, and evaluated.

\section{Future Research}

In terms of future research, the current study can contribute by highlighting the different research approaches to inclusion for adolescents with ASC. Further, it raises several questions: Whose perspective prevails and sets the foundation in the process of decision-making? Are social norms involved, and, if so, which norms dominate the approaches in research? Are we creating and developing social approaches that cater to the diversity of individuals, or are we merely aiming to create acquiescent individuals who fit well into predetermined community norms? The current study contributes to the area of research by highlighting these questions as well as by validating previous research reviews (Nilholm and Göransson 2017; EA 2017), which state that the concept of inclusion is defined in various ways in research and in diverse social contexts. The focus of future research might be to explain the underlying factors that dominate the social norms, the prevailing perspectives, and approaches in the area, if they exists at all.

The research mentioned in this article highlights the importance of educational practices where there are common values and consensus regarding the inclusion concept, as well as available and flexible educational practices, which can motivate and encourage students with ASC to participate in education and social life at school. Perhaps this can become a reality, or at least support the design of better education practices for students with ASC, when it is considered through the lens of Universal Design for Learning, where the framework of a universal education practice is already designed at an initial stage to meet the diversity of students (Meyer et al. 2014). According to Hall et al. (2012), an inclusive society enables the participation of all citizens without restrictions, which starts with an inclusive and accessible school that embraces and celebrates diversity.

Acknowledgments This study is a part of a doctoral dissertation containing a compilation of articles. It is part of the Swedish National Research School Special Education for Teacher Educators (SET), funded by the Swedish Research Council (grant no. 2017-06039), for which the author is grateful. The author wishes to thank main supervisor Professor Mona Holmqvist, Malmö University, Sweden, and co supervisor Dr. Daniel Östlund, Kristianstad University, Sweden, for accurate and rewarding guidance during the process of performing this study.

Funding Information Open access funding provided by Malmö University.

Open Access This article is licensed under a Creative Commons Attribution 4.0 International License, which permits use, sharing, adaptation, distribution and reproduction in any medium or format, as long as you give appropriate credit to the original author(s) and the source, provide a link to the Creative Commons licence, and indicate if changes were made. The images or other third party material in this article are included 
in the article's Creative Commons licence, unless indicated otherwise in a credit line to the material. If material is not included in the article's Creative Commons licence and your intended use is not permitted by statutory regulation or exceeds the permitted use, you will need to obtain permission directly from the copyright holder. To view a copy of this licence, visit http://creativecommons.org/licenses/by/4.0/.

\section{References}

American Psychiatric Association (2000). Diagnostic and statistical manual of mental disorders (4th ed., text rev.). Washington, DC: Author.

Able, H., Sreckovic, M. A., Schultz, T. R., Garwood, J. D., \& Sherman, J. (2015). Views from the trenches: teacher and student supports needed for full inclusion of students with ASD. Teacher Education and Special Education, 38(1), 44-57.

Antonovsky, A. (1987). Unraveling the mystery of health: how people manage stress and stay well. San Francisco: Jossey-Bass.

Bagatell, N. (2004). Constructing identities in social worlds: stories from four adults with autism. $\mathrm{PhD}$ dissertation: University of Southern California.

Baines, A. (2012). Positioning, strategizing, and charming: how students with autism construct identities in relation to disability. Disability and Society, 27(4), 547-536.

Barnard, J., Prior, A., \& Potter, D. (2000). Autism and inclusion: is it working? London: National Autistic Society.

Baron-Cohen, S. (2005). Theory of mind and autism: a fifteen year review. In S. Baron-Cohen, H. Tager-Flusberg, \& D. J. Cohen (Eds.), Understanding other minds: perspectives from developmental cognitive neuroscience (2nd ed., pp. 3-20). New York: Oxford University Press.

Berney, T. (2004). Asperger syndrome from childhood into adulthood. Advances in Psychiatric Treatment, 10, 341-351.

Bolman, W. M. (2008). Brief report: 25-year follow-up of a highfunctioning autistic child. Journal of Autism and Developmental Disorders, 38, 181-183.

Booth, T., \& Ainscow, M. (2002). Index for inclusion: developing learning and participation in schools. Bristol: Centre for Studies in Inclusive Education.

Bryman, A. (2015). Social research methods (5th ed.). New York: Oxford University Press.

Burchardt, T. (2004). Capabilities and disability: the capabilities framework and the social model of disability. Disability and Society, 19, 735-751.

Cameron, D., \& Cook, B. (2013). General education teachers' goals and expectations for their included students with mild and severe disabilities. Education and Training in Autism and Developmental Disabilities, 48(1), 18-30.

Carrington, S., Templeton, E., \& Papinczak, T. (2003). Adolescents with Asperger syndrome and perceptions of friendship. Focus on Autism and Other Developmental Disabilities, 18, 211-218.

Chen, Y., Bundy, A., Cordier, R., Chien, Y., \& Einfeld, S. (2016). The experience of social participation in everyday contexts among individuals with autism spectrum disorders: an experience sampling study. Journal of Autism and Developmental Disorders, 46(4), 1403-1414

Chung, Y., Carter, E., \& Sisco, L. (2012). Social interactions of students with disabilities who use augmentative and alternative communication in inclusive classrooms. American Journal of Intellectual and Developmental Disabilities, 117(5), 349-367.

Chung, W., Edgar-Smith, S., Palmer, B., Chung, S., DeLambo, D., \& Huang, W. (2015). An examination of in-service teacher attitudes towards students with autism spectrum disorder: implications for professional practice. Current Issues in Education, 18(2), 1-12.

Cronin, A., \& Mandich, M. B. (2015). Human development and performance throughout the lifespan. Clifton Park, New York: Thomson Delmar Learning.

Eldara, E., Talmora, R., \& Wolf-Zukermana, T. (2010). Successes and difficulties in the individual inclusion of children with autism spectrum disorder (ASD) in the eyes of their coordinators. International Journal of Inclusive Education, 14(1), 97-114.

European Agency for Special Needs and Inclusive Education (2018). Evidence of the link between inclusive education and social inclusion: a review of the literature. https://www.european-agency.org/ sites/default/files/Evidence\%20\%E2\%80\%93\%20A\%20Review\% 20of\%20the\%20Literature_0.pdf (21-12-2018).

Farley, M. A., McMahon, W. M., Fombonne, E., Jenson, W. R., Miller, J., Gardner, M., et al. (2009). Twenty-year outcome for individuals with autism and average or near-average cognitive abilities. Autism Research, 2(2), 109-118.

Falkmer, M, Parsons, R., and Granlund, M. (2012). Looking through the Same Eyes? Do Teachers' Participation Ratings Match with Ratings of Students with Autism Spectrum Conditions in Mainstream Schools? Autism research and treatment. https://doi.org/10.1155/ 2012/656981.

Falkmer, M., Oehlers, K., Granlund, M., \& Falkmer, T. (2015). Can you see it too? Observed and self-rated participation in mainstream schools in students with and without autism spectrum disorders. Developmental Neurorehabilitation, 18(6), 365-374.

Farmer, T., McAuliffe Lines, M., \& Hamm, J. (2011). Revealing the invisible hand: the role of teachers in children's peer experiences. Journal of Applied Developmental Psychology, 32, 247-256.

Fitzgerald, H. (2012). Drawing on disabled students' experiences of physical education and stakeholder responses. Sport, Education and Society, 17(4), 443-462.

Foster, M., \& Pearson, E. (2012). Is inclusivity an indicator of quality of care for children with autism in special education? Pediatrics, 130(2), p 17.

Foucalt, M. (1972). The archaeology of knowledge. London: Tavistock.

Gillott, A., Furniss, F., \& Walter, A. (2001). Anxiety in high-functioning children with autism. Autism, 5(3), 277-286.

Goldingay, S., Stagnitti, K., Sheppard, L., McGillivray, J., McLean, B., \& Pepin, G. (2013). An intervention to improve social participation for adolescents with autism spectrum disorder: pilot study. Developmental Neurorehabilitation, 18(2), 122-130.

Gotham, K., Bishop, S., Brunwasser, S., \& Lord, C. (2014). Rumination and perceived impairment associated with depressive symptoms in a verbal adolescent-adult ASD sample. Autism Research, 7(3), 381391.

Hall. T. E., Meyer, A., and Rose, D. H. (Eds.). (2012). Universal design for learning in the classroom: practical application. Guildford Press.

Hart, R. (1992). Children's participation: from tokenism to citizenship. Florence, Italy: UNICEF International Child Development Center.

Hebron, J., \& Humphrey, N. (2014). Mental health difficulties among young people on the autistic spectrum in mainstream secondary schools: a comparative study. Journal of Research in Special Educational Needs, 14(1), 22-32.

Horrocks, J. L., White, G., \& Roberts, L. (2008). Principals' attitudes regarding inclusion of children with autism in Pennsylvania public schools. Journal of Autism and Developmental Disorders, 38(8), 1462-1473.

Huang, A., \& Wheeler, J. (2007). Including children with autism in general education in China. Childhood Education, 83(6), 356-359.

Howard, B., Cohn, E., \& Orsmond, G. (2006). Understanding and negotiating friendships: perspectives from an adolescent with Asperger syndrome. Autism, 10(6), 619-627.

Humphrey, N., \& Symes, W. (2014). Inclusive education for pupils with autistic spectrum disorders in secondary mainstream schools: 
teacher attitudes, experience and knowledge. International Journal of Inclusive Education, 17(1), 32-46.

Hwang, S., Kim, Y. S., Koh, Y. J., \& Leventhal, B. L. (2018). Autism spectrum disorder and school bullying: who is the victim? Who is the perpetrator? Journal of Autism and Developmental Disorders, 48(4), 225-238.

Kern Koegel, L., Ashbaugh, K., Koegel, R. L., and Detarp, W., J. (2013). Increasing Socialization in Adults with Asperger's Syndrome. Psychology in the Schools, 50(9). https://doi.org/10.1002/pits. 21715.

Kirk, D. (2005). Physical education, youth sport and lifelong participation: the importance of early learning experiences. European Physical Education Review, 11(3), 239-255. https://doi.org/10. 1177/1356336X05056649.

Krieger, B., Pisikur, B., Schulze, C., Jakobs, U., Beurskens, A., \& Moser, A. (2017). Supporting and hindering environments for participation of adolescents diagnosed with autism spectrum disorder: a scoping review. PLoS One, 13(8), 1-30.

Kurth, J., \& Mastergeorge, A. (2010). Academics and cognitive profiles of students with autism: implications for classroom practice and placement. International Journal of Special Education, 25(2), 8-14.

Lamb, P., Firbank, D., \& Aldous, D. (2016). Capturing the world of physical education through the eyes of children with autism spectrum disorders. Sport, Education and Society, 21(5), 698-722.

Lee, H. J., \& Park, H. R. (2007). An integrated literature review on the adaptive behavior of individuals with Asperger syndrome. Remedial and Special Education, 28, 132-139.

Locke, J., Ishijima, E. H., Kasari, C., \& London, N. (2010). Loneliness, friendship quality and the social networks of adolescents with highfunctioning autism in an inclusive school setting. Journal of Research in Special Educational Needs, 10, 74-81.

Lounds Taylor, J., Adams, R., \& Bishop, S. (2018). Social participation and its relation to internalizing symptoms among youth with autism spectrum disorder as they transition from high school. Autism Research, 10(4), 663-672.

Meyer, A., Rose, D. H., \& Gordon, D. T. (2014). Universal design for learning: theory and practice. CAST Professional Publishing.

Myers, E., Davis, B., Stobbe, G., \& Bjornson, K. (2015). Community and social participation among individuals with autism spectrum disorder transitioning to adulthood. Journal of Autism and Developmental Disorders, 45(8), 2373-2381.

Mesibov, G., \& Shea, V. (1996). Full inclusion and students with autism. Journal of Autism and Developmental Disorders, 26(3), 337-346.

Meyer, J. A., Mundy, P. C., Vaughan Van Hecke, A., \& Durocher, J. S. (2006). Social attribution processes and comorbid psychiatric symptoms in children with Asperger syndrome. Autism, 10(4), 383-402.

Munkhagen, E., Gjevik, E., Pripp, A., Sponheim, E., \& Dieseth, T. (2017). School refusal behaviour: are children and adolescents with autism spectrum disorder at a higher risk? Research in Autism Spectrum Disorders, 41, 31-38.

Müller, E., Schuler, A., \& Yates, G. B. (2008). Social challenges and supports from the perspective of individuals with Asperger syndrome and other autism spectrum disabilities. Autism, 12(2), 173190.

Myles, B. S. (2005). Children and youth with Asperger syndrome: strategies for success in inclusive settings. Thousand Oaks, CA: Corwin Press.

Myles, B. S., Lee, H. J., Smith, S. M., Tien, K., Chou, Y., Swanson, T. C., \& Hudson, J. (2007). A large-scale study of the characteristics of Asperger syndrome. Education and Training in Developmental Disabilities, 42, 448-459.

Nilholm, C., \& Göransson, K. (2017). What is meant by inclusion? An analysis of European and North Americal journal articles with high impact. European Journal of Special Needs Education, 32(3), 437445.
Norwich, B. (2005). Inclusion: is it a matter of evidence about what works or about values and rights? Education, 3-13(33), 51-56.

Oliver, M. (1990). The individual and social models of disability. Paper presentation. Joint workshop of the living options group and the research unit of the Royal College of Physicians, 23rd July 1990. https://disability-studies.leeds.ac.uk/wp-content/uploads/sites/40/ library/Oliver-in-soc-dis.pdf (21-12-2018).

Portway, S., \& Johnson, B. (2003). Asperger syndrome and the children who "don't quite fit". Early Child Development and Care, 173(3), 435-443.

Reed, P., \& Osborne, L. A. (2014). Mainstream education for children with autism spectrum disorders. In J. Tarbox, D. R. Dixon, P. Sturmey, \& J. L. Matson (Eds.), Handbook of early intervention for autism spectrum disorders (pp. 447-485). New York: Springer.

Rosso, E. (2016). Brief report: coaching adolescents with autism spectrum disorder in a school-based multi-sport program. Journal of Autism and Developmental Disorders, 46(7), 2526-2531.

Sansosti, F. J. (2012). Reducing the threatening and aggressive behavior of a middle school student with Asperger's syndrome. Preventing School Failure, 12, 8-18.

Sansosti, F. J., Powell-Smith, K. A., \& Cowan, R. J. (2010). High functioning autism/Asperger syndrome in schools: assessment and intervention. New York, NY: Guilford Press.

Smith, A. (2004). The inclusion of pupils with special educational needs in secondary school physical education. Physical Education and Sport Pedagogy, 9(1), 37-54. https://doi.org/10.1080/ 1740898042000208115.

Sreckovic, M., Brunsting, N., \& Able, H. (2014). Victimization of students with autism spectrum disorder: a review of prevalence and risk factors. Research of Autism Spectrum Disorders, 8, 1155-1172. https://doi.org/10.1016/j.rasd.2014.06.004.

Fernando, S., \& Perera, H. (2012). School refusal: behavioural and diagnostic profiles of a clinical sample. Sri Lanka Journal of Psychiatry, $3(1), 10-13$.

Taheri, A., Perry, A., \& Minnes, P. (2017). Exploring factors that impact activity participation of children and adolescents with severe developmental disabilities. Journal of Intellectual Disability Research, 61(12), 1151-1161.

Tennant, J., Demaray, M., Malecki, C., Terry, M., Clary, M., \& Elzinga, N. (2014). Students' ratings of teacher support and academic and social-emotional well-being. School Psychology Quarterly, 30(4), 494-512.

Twachtman-Cullen, D., Baron, G., Groden, J., Groden, G., \& Lipsitt, L. (2006). Communication and stress in students with autism spectrum disorders. Oxford: Oxford University Press.

Vandell, D., Pierce, K., \& Dadisman, K. (2005). Out-of-school settings as a developmental context of children and youth. Advances in Child Development and Behavior, 33, 43-77.

Watkins, L., O’Reilly, M., Kuhn, M., Gevarter, C., Lancioni, G., Sigafoos, J., et al. (2015). A review of peer-mediated social interaction interventions for students with autism in inclusive settings. Journal of Autism and Developmental Disorders, 45(4), 1070 1083.

Whitaker, P. (2002). Supporting families of preschool children with autism. Autism, 6(4), 411-426.

Wiley, A., Cook, B., \& Rumrill, P. (2011). Research in special education. Springfield: Charles C. Thomas Publisher, Limited.

Woff, S. (2004). The History of Autism. European Child \& Adolescent Psychiatry, 13(4), 201-208.

Wong, S. (2017). Challenges encountered by 17 autistic young adults in Hong Kong. Support for Learning, 32(4), 375-386.

Publisher's Note Springer Nature remains neutral with regard to jurisdictional claims in published maps and institutional affiliations. 